\title{
NF-кB p50-deficient immature myeloid cell (p50-IMC) adoptive transfer slows the growth of murine prostate and pancreatic ductal carcinoma
}

\author{
Rahul Suresh, David J Barakat, Theresa Barberi, Lei Zheng, Elizabeth Jaffee, \\ Kenneth J Pienta, Alan D Friedman
}

To cite: Suresh R, Barakat DJ, Barberi T, et al. NF-KB p50deficient immature myeloid cell (p50-IMC) adoptive transfer slows the growth of murine prostate and pancreatic ductal carcinoma. Journal for ImmunoTherapy of Cancer 2020;8:e00244. doi:10.1136/ jitc-2019-000244

- Additional material is published online only. To view, please visit the journal online (http://dx.doi.org/10.1136/jitc2019-000244).

Accepted 15 December 2019

\section{Check for updates}

(C) Author(s) (or their employer(s)) 2020. Re-use permitted under CC BY-NC. No commercial re-use. See rights and permissions. Published by BMJ.

Johns Hopkins University School of Medicine, Baltimore, Maryland, USA

Correspondence to

Dr Alan D Friedman; afriedm2@jhmi.edu

\section{ABSTRACT}

Background Macrophages and dendritic cells lacking the transcription factor nuclear factor kappa B p50 are skewed toward a proinflammatory phenotype, with increased cytokine expression and enhanced T cell activation; additionally, murine melanoma, fibrosarcoma, colon carcinoma, and glioblastoma grow slower in ${\mathrm{p} 50^{-/-}}^{-1}$ mice. We therefore evaluated the efficacy of p50-negative immature myeloid cells (p50-IMCs) adoptively transferred into tumor-bearing hosts. Immature cells were used to maximize tumor localization, and pretreatment with 5-fluorouracil (5FU) was examined due to its potential to impair marrow production of myeloid cells, to target tumor myeloid cells and to release tumor neoantigens.

Methods Wild-type (WT)-IMC or p50-IMC were generated by culturing lineage-negative marrow cells from WT or $\mathrm{p} 50^{-/-}$mice in media containing thrombopoietin, stem cell factor and Flt3 ligand for 6 days followed by monocyte colony-stimulating factor for 1 day on ultralow attachment plates. Mice inoculated with Hi-Myc prostate cancer (PCa) cells or K-Ras ${ }^{\mathrm{G} 12 \mathrm{D}}$ pancreatic ductal carcinoma (PDC)luciferase cells received $5 \mathrm{FU}$ followed 5 days later by three doses of $10^{7}$ immature myeloid cells (IMC) every 3-4 days. Results PCa cells grew slower in $\mathrm{p} 50^{-/-}$mice, and absence of host $p 50$ prolonged the survival of mice inoculated orthotopically with PDC cells. IMC from Cytomegalovirus (CMV)-luciferase mice localized to tumor, nodes, spleen, marrow, and lung. 5FU followed by p50-IMC slowed PCa and PDC tumor growth, 3-fold on average, in contrast to 5FU followed by WT-IMC, 5FU alone or p50-IMC alone. Slowed tumor growth was evident for $93 \%$ of $\mathrm{PCa}$ but only $53 \%$ of PDC tumors; we therefore focused on PCa for additional IMC analyses. In PCa, p50-IMC matured into $\mathrm{F} 4 / 80^{+}$macrophages, as well as CD11 $\mathrm{b}^{+} \mathrm{F} 4 / 80^{-} \mathrm{CD}_{11 \mathrm{C}^{+}}$ conventional dendritic cells (cDCs). In both tumor and draining lymph nodes, p50-IMC generated more macrophages and cDCs than WT-IMC. Activated tumor $\mathrm{CD}^{+} \mathrm{T}$ cells were increased fivefold by p50-IMC compared with WT-IMC, and antibody-mediated $\mathrm{CD}^{+} \mathrm{T}$ cell depletion obviated slower tumor growth induced by $5 \mathrm{FU}$ followed by p50-IMC.

Conclusions 5FU followed by p50-IMC slows the growth of murine prostate and pancreatic carcinoma and depends on $\mathrm{CD}^{+} \mathrm{T}$ cell activation. Deletion of $\mathrm{p} 50$ in patientderived marrow $\mathrm{CD}_{3} 4^{+}$cells and subsequent production of
IMC for adoptive transfer may contribute to the therapy of these and additional cancers.

\section{INTRODUCTION}

Myeloid cells are a heterogeneous group of cells that belong to the innate immune system. Among them, macrophages and dendritic cells (DCs) directly control $\mathrm{T}$ cell responses. Multiple solid tumors secrete chemokines, for example, CCL2, and cytokines, such as monocyte colony-stimulating factor (M-CSF) or interleukin (IL)-4, that attract circulating monocytes and induce their maturation into M2-polarized tumor-associated macrophages (TAMs); M2 TAMs suppress antitumor $\mathrm{T}$ cell immunity and secrete tumor-promoting growth factors, proangiogenic VEGF, and proinvasive matrix metalloproteases. ${ }^{12} \mathrm{M}-\mathrm{CSF}$ receptor tyrosine kinase inhibitors that induce proinflammatory M1 TAM activation are under clinical investigation; however, resistance to such agents can arise via tumor secretion of alternative M2-polarizing cytokines. ${ }^{3-5}$ Targeting non-redundant transcription factors critical for maintenance of the M2 gene expression programme may prove more effective.

Nuclear factor kappa B (NF-kB) subunits dimerize and bind DNA via their Rel homology domains. Under basal conditions, NF- $\mathrm{KB}$ p65 (RelA) and c-Rel are held in the cytoplasm

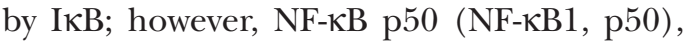
which lacks a transactivation domain and has much lower affinity for IKB, enters the nucleus to bind DNA and repress transcription in cooperation with histone deacetylases (HDACs) and Bcl-3. Proinflammatory cytokines such as tumor necrosis factor alpha $(\mathrm{TNF} \alpha)$ initiate canonical signalling, leading to phosphorylation of IKB followed by ubiquitination and proteasomal degradation, thereby allowing complexes such as p65:p65 
and p65:p50 to enter the nucleus, displace repressive p50:p50 homodimers, and induce proinflammatory gene expression. ${ }^{6-8}$

In myeloid cells with reduced or absent $\mathrm{p} 50, \mathrm{NF}-\kappa \mathrm{B}$ target genes are de-repressed due to the absence of chromatinbound p50:p50:HDAC or p50:p50:Bcl-3 complexes. Proinflammatory gene induction by p50 ( Nfkb1) gene deletion or RNA knockdown leads to activation of macrophages, as well as DCs, favouring $\mathrm{T}$ cell activation. ${ }^{9-14}$ Melanoma, fibrosarcoma, colon cancer, and glioblastoma cells grow slower in syngeneic $\mathrm{p} 50^{-/-}$than wild-type (WT) recipients; TAMs are reprogrammed from M2 to M1; and tumor T cells are more activated. ${ }^{91516}$ Prostate cancer (PCa) and pancreatic ductal carcinoma (PDC) also contain evident M2 TAMs, which are correlated with poor prognosis. ${ }^{17} 18$ Adding to these findings, we demonstrate slower growth of subcutaneous Hi-Myc PCa and prolonged survival after orthotopic inoculation of K-Ras ${ }^{\mathrm{G} 12 \mathrm{D}}$ PDC into $\mathrm{p} 50^{-/-}$ compared with WT hosts.

Specifically inhibiting p50 at the protein level without affecting the homologous RelA or c-Rel may prove problematic, and p50 inhibition in tumor cells may favour tumor growth. ${ }^{6}$ We ultimately envision a cellular therapy wherein patient-derived myeloid cells are expanded ex vivo while targeting their p50 gene or mRNA and then reinfused. Infusion of murine marrow monocytes polarized to an immunosuppressive state reduces graft versus host disease, with biallelic mutation in the ASC inflammasome gene providing greater protection by preventing in vivo conversion to the M1 phenotype. ${ }^{19}$ Analogously, we expect that myeloid cells lacking p50 will be 'locked' in an activated antitumor state. To model this approach, we have expanded lineage-negative $\left(\mathrm{Lin}^{-}\right)$murine marrow cells from WT or $\mathrm{p} 50^{-/-}$mice for 6-8 days using thrombopoietin (TPO), stem cell factor (SCF), and Flt3 ligand (FL), cytokines which maintain stem and progenitor cell immaturity. Next, cells were cultured with M-CSF for 1 day on ultralow attachment plates to generate immature myeloid cells (IMC) and to prevent macrophage maturation..$^{20}$ IMCs were then infused, avoiding provision of mature macrophages that might less efficiently reach the tumor. We also evaluated pretreatment with 5-fluorouracil $(5 \mathrm{FU})$ at a dose that induces a nadir of host white blood cells starting 4 days later and lasts 1 week, ${ }^{21}$ analogous to lymphodepletion prior to adoptive $\mathrm{T}$ cell transfer. In addition, 5FU targets immunosuppressive tumor myeloid cells $^{22}$ and may release PCa or PDC neoantigens to further enhance antitumor response.

We have determined that $5 \mathrm{FU}$ followed by three infusions of p50-negative IMC (5FU/p50-IMC) slows the growth of Hi-Myc PCa and K-Ras ${ }^{\text {G12D }}$ PDC tumors, in contrast to 5FU/WT-IMC, p50-IMC alone, or 5FU alone. Infused cells mature in vivo into activated tumor and lymph node macrophages and conventional dendritic cells (cDCs). Additionally, 5FU/p50-IMC increased numbers of activated tumor $\mathrm{CD}^{+} \mathrm{T}$ cells, and $\mathrm{CD} 8^{+} \mathrm{T}$ cell depletion eliminated the therapeutic efficacy of 5FU/ p50-IMC.

\section{METHODS}

\section{Mice}

Male WT C57BL/6 (B6) CD45.1 or CD45.2 mice of 8-12 weeks were obtained from Charles River Laboratory (Kingston, New York, USA) as PCa recipients. Male and female WT or $\mathrm{p} 50^{-/-} \mathrm{B} 6$ mice of $8-16$ weeks were used as IMC donors. Male WT albino B6 mice (\#58) of 8-12 weeks to be used for PDC recipients, p50 $0^{-/-}$mice (\#6097), and B6 Cytomegalovirus (CMV)-Luc mice (\#25854) were obtained from Jackson Laboratory (Bar Harbor, Maine, USA). Mice were housed in individually ventilated cages at $22^{\circ} \mathrm{C}$ with a 12 hours' light/dark cycle, five mice per cage, and were given acidified water and Envigo 2018SX autoclaved feed. Mice of the same sex and age, 24-26 g, were used as cancer cell recipients.

\section{Tumor cell inoculation and in vivo monitoring}

B6 Hi-Myc PCa cells and UN-KC-6141 KRas ${ }^{\mathrm{G} 12 \mathrm{D}}$;Pdx1-Cre PDC cells have been described and were kindly provided by BW Simons and SK Batra, respectively. ${ }^{23}{ }^{24}$ PCa cells were maintained in WT male mice by serial subcutaneous (SQ) passage every 3-4 weeks or inoculated into WT or p50 $0^{-/}$male mice for experiments as described.$^{23}$ In brief, PCa tumors were harvested after euthanasia, minced, placed in Dulbecco's modified Eagle medium (DMEM) / F12 with 10\% fetal bovine serum (FBS), Collagenase/ Hyaluronidase, Dispase, and DNase I (Stem Cell Technologies). After incubation at $37^{\circ} \mathrm{C}$ for 1 hour, cells were passed through a $40 \mu \mathrm{M}$ strainer, pelleted, resuspended at $2 \times 10^{6}$ viable cells per $100 \mu \mathrm{L}$ phosphate-buffered saline (PBS) / mouse, and injected into the flanks of recipients. Tumor growth was monitored 2- to 3-times weekly using callipers, with tumor volumes estimated as length $\mathrm{x}$ width $\mathrm{x}$ height $\mathrm{x} \Phi / 6 .^{23}$ Mice were euthanized when tumors reached $2.0 \mathrm{~cm}$ in maximal linear dimension or became ulcerated.

PDC cells were cultured in vitro using DMEM with $10 \%$ FBS, $1 \%$ non-essential amino acids, $1 \%$ sodium pyruvate, and penicillin $(100 \mathrm{U} / \mathrm{mL})$-streptomycin $(100 \mu \mathrm{g} /$ $\mathrm{mL})$. PDC-Luc cells were generated by transfection with NotI-linearized pGL4.51-CMV-Luc2neo (Promega) using Lipofectamine 2000 (Invitrogen) followed by selection in $0.6 \mathrm{mg} / \mathrm{mL} \mathrm{G} 418$, subcloning by limiting dilution, and screening by luciferase assay to identify a single clone that was used for these studies. For orthotopic PDC inoculation, after inducing anaesthesia with ketamine and xylazine, a $1 \mathrm{~cm}$ incision was made in the left flank and a $5 \mathrm{~mm}$ incision in the peritoneum. The entire pancreatic body together with spleen was pulled out using bluntnose forceps, $0.5 \times 10^{6} \mathrm{PDC}$ in $40 \mu \mathrm{l}$ of 1:1 PBS:Matrigel (Corning 354234) was injected into the pancreatic tail using a Hamilton syringe with a $30 \mathrm{~g}$ needle, and the muscle layer and skin were closed with 4-0 absorbable sutures. For PDC-Luc tumor imaging, after shaving the abdominal wall mice were injected intra-peritoneally (IP) with luciferin $(150 \mu \mathrm{g} / \mathrm{g})$ in PBS; $10 \mathrm{~min}$ later mice were anaesthetized with isofluorane-oxygen gas and imaged using the Spectrum in vivo imaging system (IVIS, Perkin 
Elmer). To allow repeated imaging of albino mice, the shaved abdominal wall was treated with Nair every 2 weeks.

\section{IMC generation}

To generate IMC, marrow mononuclear cells were obtained by crushing the long bones, hips, and spine in PBS with 2\% FBS. Red blood cells were lysed using ammonium chloride. Marrow was then lineage-depleted using biotin-conjugated B220, Gr-1, CD11b, Ter119, and CD3 mouse antibody Lineage Cocktail (BD Biosciences), anti-biotin microbeads, and LD columns (Miltenyi Biotec). Lin $^{-}$cells were then cultured for 6-8 days with Iscove's Modified Dulbecco Medium (IMDM), 10\% heatinactivated FBS, murine SCF $(30 \mathrm{ng} / \mathrm{mL})$, murine TPO $(10 \mathrm{ng} / \mathrm{mL})$, and murine FL $(30 \mathrm{ng} / \mathrm{mL})$, followed by transfer to IMDM with $10 \%$ HI-FBS and murine M-CSF $(20 \mathrm{ng} / \mathrm{mL})$, or alternatively with granulocyte-monocyte colony-stimulating factor (GM-CSF, $1 \mathrm{ng} / \mathrm{mL}$ ) and FL $(30 \mathrm{ng} / \mathrm{mL})$, for 24 hours on Ultra-low attachment sixwell plates (Corning, \#3471). Non-adherent cells, designated as IMC, were then collected and washed with PBS prior to infusion of $10^{7}$ cells in $200 \mu \mathrm{L}$ PBS per dose by tail vein injection. $5 \mathrm{FU}$ was given at $150 \mathrm{mg} / \mathrm{kg}$ IP using a $7.5 \mathrm{mg} / \mathrm{mL}$ solution in normal saline 5 days prior to the first IMC injection. To deplete $\mathrm{CD} 8^{+} \mathrm{T}$ cells, mice received rat-anti-CD8 antibody (Bio-X-Cell, BE0223) at $100 \mathrm{ug} /$ dose IP twice weekly beginning 1 day prior to the first IMC injection.

\section{Flow cytometry}

PCa tumors were dissociated as done for cell inoculation; lymph node and spleens were treated with Collagenase/ Hyaluronidase for $30 \mathrm{~min}$ and then passed through a $40 \mu \mathrm{L}$ cell strainer. Marrow cells were subjected to red cell lysis. To induce $\mathrm{T}$ cell activation, total tumor cells were incubated for 4 hours in DMEM/10\% FBS with Cell Stimulation Cocktail (eBioscence) containing phorbol myristate acetate (PMA)/ionomycin with brefeldin A and monensin protein transport inhibitors, or with the inhibitors alone. These cell populations and IMC were stained with surface antibodies on ice after 15 min 1:50 Fc $\gamma \mathrm{R}$ blockade (eBioscience). Cells were analyzed by flow cytometry (FC) using an LSRFortessa flow cytometer (BD Biosciences) gating on cells that excluded Live/Dead Aqua dye (ThermoFisher). For T cells, intracellular interferon $\gamma($ IFN $\gamma$ ) staining was done after surface staining using the FoxP3 kit (eBioscience). Antibodies used were anti-CD45.1-PE (A20), anti-CD45.2-BV650 (104), antiLy6G-FITC (1A8), anti-CD11c-PE/Dazzle594 (N418), anti-F4/80-APC (BM8), anti-Ly6C-AF700 (HK1.4), anti-MR-PE-Cy7 (068C2), anti-Flt3-BV421 (A2F10), anti-CD115-PE (AFS98), anti-CD3-AF488 (17A2), antiCD8-BV650 (53-6.7), and anti-IFN $\gamma$-APC (XMG1.2) from BioLegend, anti-CD11b-PerCP-Cy5.5 (M1/70), anti-CD19-AlexaFluor 647 (1D3), and anti-CD4-BUV496 (GK1.5) from BD Biosciences, and anti-Major Histocompatibility Complex II(MHCII)-eFluor450 (M5/114.15.2) and anti-PD-1-PE-Cy7 (J43) from eBioscience. IMC cell morphology was visualized by Wright's-Giemsa staining of cell cytospins.

\section{Statistics}

Tumor volumes at a given time point and $\mathrm{T}$ cell subsets were compared using the Student t-test (Excel 2016), with means and standard errors (SE) shown. In addition, tumor growth was fit to an exponential model using linear mixed effects analysis package lme $4,{ }^{25}$ with pairwise p-values obtained at specific time points after correcting for multiple comparisons using Tukey's method using emmeans V.1.4.1. ${ }^{26}$ Adjusted $p$ value $<0.05$ was considered significant. Survival curves were generated using Survival Analysis in R V.2.38 ${ }^{27}$ and compared using the Log Rank test. In most instances, five mice were studied per condition in each experiment. The number of experimental replicates, the total number of mice analyzed per experimental condition, and whether results shown are from combining data from more than one replicate are delineated in the figure legends.

\section{RESULTS}

Absence of host p50 slows PCa growth and prolongs survival after PDC inoculation

We first evaluated whether absent host p50 impacts murine PCa and PDC tumor growth. Hi-Myc PCa cells were inoculated into the flanks of syngeneic B6 WT or $\mathrm{p} 50^{-/-}$mice and tumor sizes were monitored once they became palpable, with volume of at least $0.015 \mathrm{~cm}^{3}$, which first occurred on day 21 (figure 1A, left). To account for all the data, measured tumor volumes were fit to an exponential model of tumor growth, with the resulting semi-log plots of tumor volume versus time and their $95 \%$ confidence intervals shown (figure 1A). Comparison of tumor sizes, as predicted by the exponential model, demonstrates a statistically significant, 3- to 16-fold, reduction in PCa tumor volume in the $\mathrm{p} 50^{-/-}$recipients between days 25 and 62, including 3.9-fold reduction $(\mathrm{p}=0.007)$ on day 33 (figure 1A, right).

K-Ras ${ }^{\text {G12D }}$ PDC cells were inoculated orthotopically into the pancreas of syngeneic $\mathrm{B} 6 \mathrm{WT}$ or $\mathrm{p} 50^{-/-}$mice and survival was monitored (figure 1B). $\mathrm{p} 50^{-/-}$hosts survived significantly longer, with the time to $50 \%$ survival increasing from 28 to 58 days. These findings demonstrate that both Hi-Myc PCa and K-Ras ${ }^{\text {G12D }}$ PDC tumors grow slower in mice lacking p50, as seen previously for melanoma, fibrosarcoma, colon cancer, and glioblastoma. ${ }^{91516}$

\section{Generation and characterization of IMCs}

We and others have identified a role for p50 in maintaining the suppressive M2 phenotype of myeloid cells. ${ }^{916}$ In an effort to exploit this role and develop a clinically-relevant therapy, we generated myeloid cells from $\mathrm{p} 50^{-/-}$marrow that could serve as a model for adoptive cell therapy in PCa, PDC, and potentially additional cancers. Terminal differentiation of myeloid cells increases expression of adhesive receptors which might limit tumor localization, 

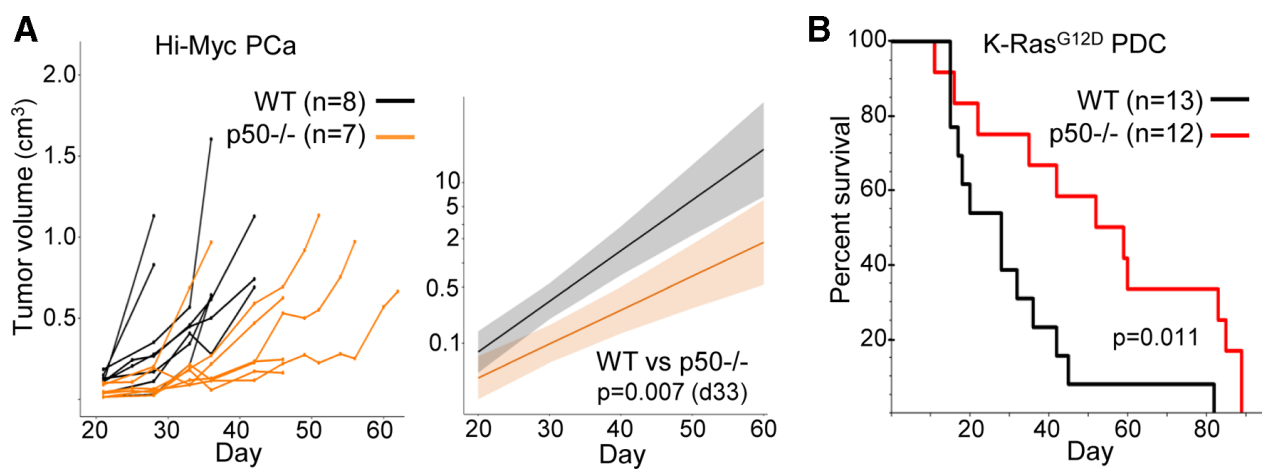

Figure 1 Absence of host nuclear factor kappa B p50 slows PCa growth and prolongs murine survival after PDC orthotopic

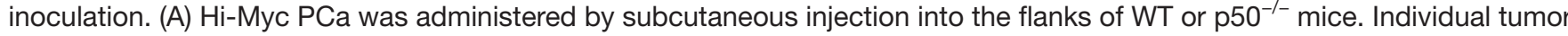
volumes as measured every 2-4 days are shown (left). These data from a single experiment were fit to an exponential model, with semilog plots with their $95 \%$ Cls shaded and comparison of expected mean tumor volumes on day 33 as predicted by

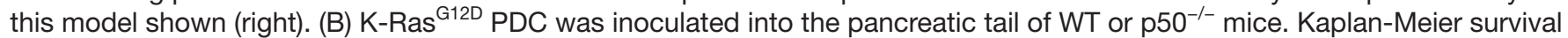
curves and log-rank $p$ values are shown, with data combined from three experiments. PCa, prostate cancer; PDC, pancreatic ductal carcinoma; WT, wild type.

as seen in previous macrophage-based cell therapies. ${ }^{28} \mathrm{We}$ therefore used less mature cells. Lin $^{-}$bone marrow mononuclear cells from WT or $\mathrm{p} 50^{-/-}$mice were expanded in media containing SCF, TPO, and FL, cytokines that maintain stem/progenitor cell immaturity. 2.5-5×10 ${ }^{6} \mathrm{Lin}^{-}$cells were obtained per mouse, and these expanded $\sim 15$ fold over 6 days, with $\mathrm{Lin}^{-}$cells from $\mathrm{p} 50^{-/-}$mice generating $\sim 20 \%$ more cells than those from WT mice. To promote monocytic maturation while minimizing macrophage formation, expanded cells were then placed in media containing M-CSF for only 1 day. Resulting IMCs generated from WT or $\mathrm{p} 50^{-/}$marrow were designated WT-IMC or p50-IMC, respectively.

Wright-Giemsa-stained cell cytospins revealed that culture in SCF, TPO, and FL for 6 days produced a blastlike morphology, and culture for one additional day in
A

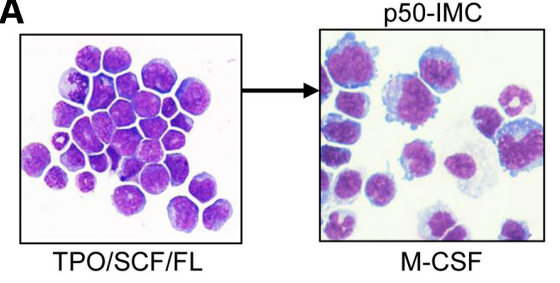

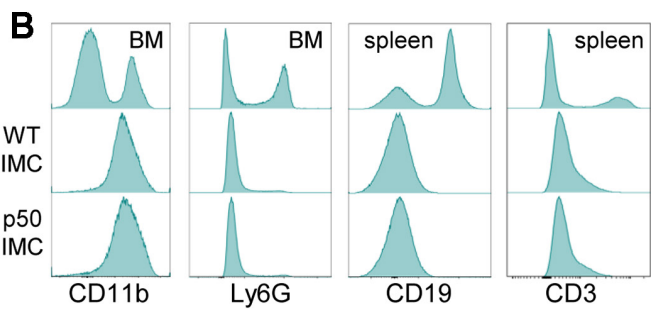

D

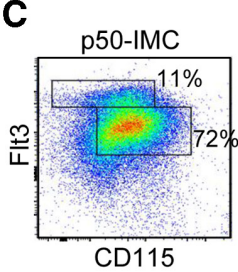

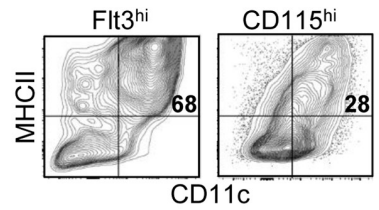

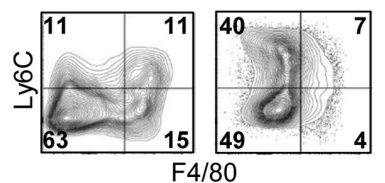

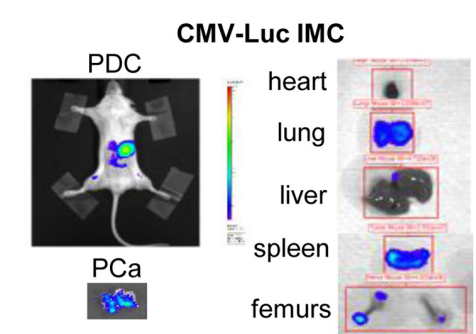

Figure 2 Characterization of marrow-derived IMCs. (A) Lineage-depleted WT or $\mathrm{p} 50^{-/-}$murine marrow mononuclear cells were expanded in IMDM/FBS with TPO, SCF and FL for 6 days and then for an addition day in IMDM/FBS with M-CSF. The morphology of p50-IMC on days 6 and 7 was evaluated by Wright's Giemsa staining of cell cytospins. (B) WT-IMC and p50IMC were evaluated by FC for CD11b, Ly6G, CD19 and CD3. BM or spleen cells provide positive controls. (C) p50-IMC were evaluated by FC for surface Flt3 and CD115 and also for MHCIl, CD11c and Ly6C, F4/80 within the Flt3 ${ }^{\text {hi }}$ and CD115 ${ }^{\text {hi }}$ gates. Data are representative of two experiments. (D) Mice inoculated with PCa or PDC on day 0 received a dose of $5 F U$ on day 18 or day 7 , respectively, followed 5 days later by infusion of IMC generated from CMV-Luc mice. After an additional 2 days, these mice received a dose of luciferin followed by in vivo imaging system imaging of a bisected PCa tumor, of a PDC tumor-bearing mouse or of isolated organs. Representative images are shown. BM, bone marrow; CMV, Cytomegalovirus; FBS, fetal bovine serum; FC, flow cytometry; FL, Flt3 ligand; IMC, immature myeloid cell; IMDM, Iscove's Modified Dulbecco Medium; M-CSF, monocyte colony-stimulating factor; MHCII, Major Histocompatibility Complex II; p50-IMC, p50-negative immature myeloid cell; PCa, prostate cancer; PDC, pancreatic ductal carcinoma; SCF, stem cell factor; TPO, thrombopoietin; WT, wild type. 
M-CSF generated cells with an immature monocyte-like morphology (figure 2A and online supplementary figure $\mathrm{S} 1 \mathrm{~A})$. Flow cytometry (FC) indicates that the vast majority of both WT-IMC and p50-IMC express the pan-myeloid surface protein CD11b and lack Ly6G, CD19, and CD3, proteins found on mature neutrophils, $\mathrm{B}$ cells, and $\mathrm{T}$ cells, respectively (figure 2B). Staining for Flt3/Flk2 (FL receptor) and CD115 (M-CSF receptor) revealed a Flt $3{ }^{\text {hi }}$ population comprising $11 \%$ of p50-IMC and $6 \%$ of WT-IMC, and a CD115 $5^{\text {hi }}$ population comprising $72 \%$ of p50-IMC and $65 \%$ of WT-IMC (figure 2C and online supplementary figure S1B). Flt3 is expressed on DC precursors, and further analysis shows that in the Flt ${ }^{\text {hi }}$ population, $68 \%$ of p50-IMC and $81 \%$ of WT-IMC co-express CD11c and MHCII, consistent with their having DC potential. In the $\mathrm{CD} 115^{\text {hi }}$ population, only $28 \%$ of p50-IMC and $43 \%$ of WT-IMC co-express CD11c and MHCII. Additionally, within the CD115 ${ }^{\text {hi }}$ population $47 \%$ of p50-IMC and $67 \%$ of WT-IMC express Ly6C, a protein found on both monocytes and macrophages, and the mature macrophage marker $\mathrm{F} 4 / 80$ is only present on $11 \%$ of CD $115^{\text {hi }}$ p50-IMC and $15 \%$ of CD115 ${ }^{\text {hi }}$ WT-IMC (figure 2C and online supplementary figure $\mathrm{S} 1 \mathrm{~B}$ ).

To evaluate the ability of IMC to reach tumors, IMC were generated from CMV-Luc mice (Luc-IMC). We administered 5FU to WT mice that had been inoculated with PCa or PDC. 5FU was chosen as its effects on murine blood counts are well-defined..$^{21}$ Five days later, at the 5 FU-induced nadir of blood counts, we infused Luc-IMC, which were then visualized by IVIS after an additional 2 days (figure 2D). Luc-IMC were evident in PCa and PDC tumors as well as the lungs, spleen, and femurs, but not in heart or liver; the bioluminescence signal in the PDC tumor was $\sim 2.5$ fold higher than that of lung or spleen (online supplementary figure $\mathrm{S1C}$ ).

\section{Fu followed by p50-IMC slows PCa tumor growth}

We next evaluated the ability of p50-IMC to slow PCa tumor growth, postulating that a preceding dose of $5 \mathrm{FU}$ would enhance p50-IMC efficacy. Hi-Myc PCa was inoculated into the flanks of syngeneic B6 male mice. Thirteen days later, when tumors were just palpable, mice received a single dose of $5 \mathrm{FU}$, followed by three intravenous injections of $10^{7}$ WT-IMC or p50-IMC on days 18, 21, and 25 , as diagrammed (figure $3 \mathrm{~A}$, top). Additional groups of mice received 5FU alone, p50-IMC alone, or neither. tumor volumes measured at individual time points for each mouse in these five experimental groups are shown (figure 3A, bottom). Measured tumor volumes were fit to an exponential model of tumor growth (figure 3B).

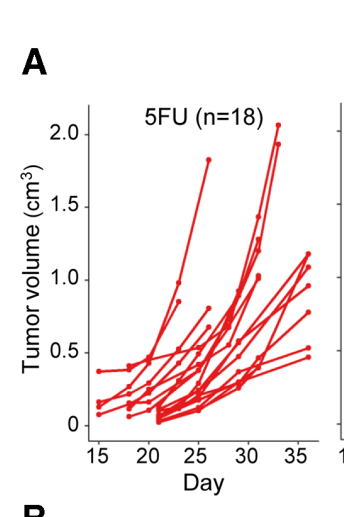

B

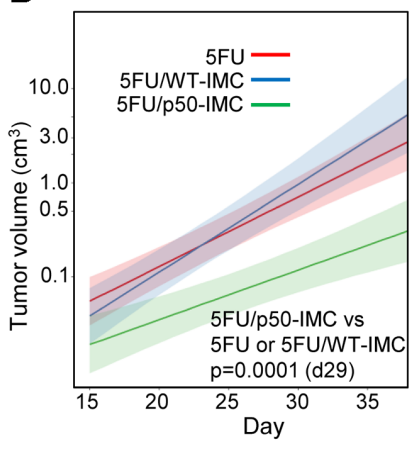

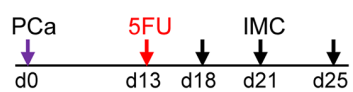
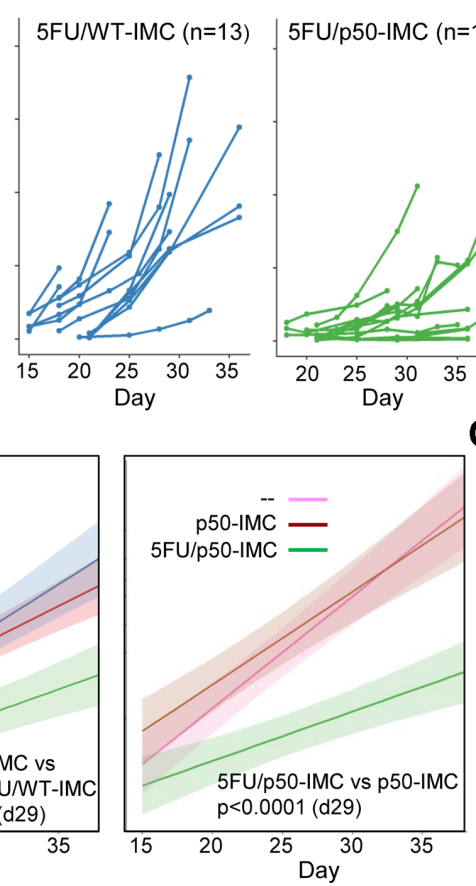

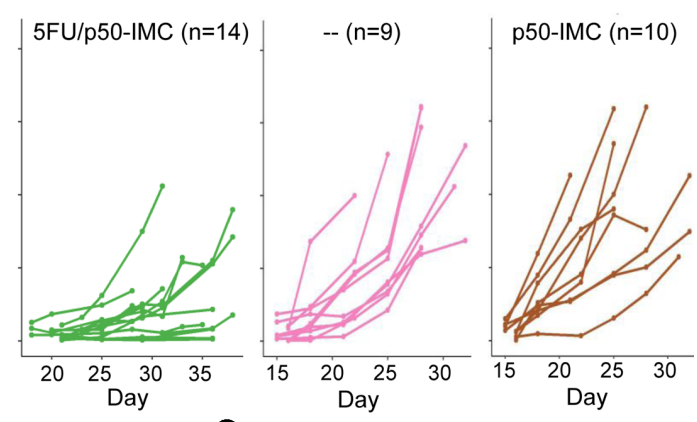

C
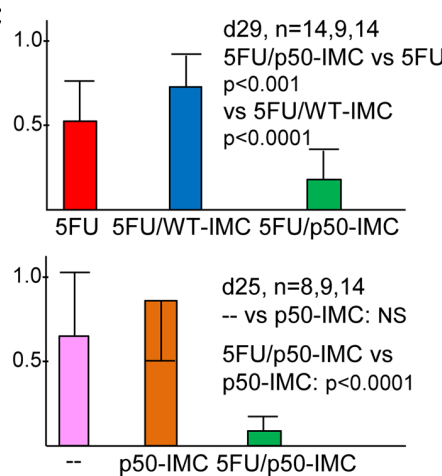

Figure 3 5FU followed by p50-IMC slows PCa tumor growth. (A) Mice inoculated SQ with Hi-Myc PCa on day 0 received 5FU on day 13 and $1 \times 10^{7}$ WT-IMC or p50-IMC on days 18,21 and 25 , as diagrammed. Additional groups of mice received $5 F U$ alone, no treatment or p50-IMC alone. Individual tumor volumes as measured every 2-4 days are shown. Results are combined from two to four experiments. (B) These data were fit to an exponential model, with semilog plots and comparison of expected mean tumor volumes between the 5FU/p50-IMC and 5FU/WT-IMC, 5FU-alone or p50-IMC-alone groups on day 29. (C) Mean tumor volumes and SEs as measured on day 29 (or day 28) for 5FU, 5FU/WT-IMC and 5FU/p50-IMC mice (top) and on day 25 for no treatment (--), p50-IMC and 5FU/p50-IMC are shown, along with the number of mice with measurable tumors in each group on those days. 5FU, 5-fluorouracil; IMC, immature myeloid cell; p50-IMC, p50-negative immature myeloid cell; PCa, prostate cancer; SQ, subcutaneous; WT, wild type. 
Between days 19 and 35, expected mean tumor volumes for the 5FU/p50-IMC group were 3- to 10-fold lower than those for both the 5FU/WT-IMC and 5FU alone groups, with $\mathrm{p}=0.0001$ on day 29 . We also compared the measured tumor volumes on day 28 or 29 between these groups. At this time, the mean volume of tumors in the $5 \mathrm{FU} / \mathrm{p} 50$ IMC group was 3-fold lower than that for the $5 \mathrm{FU}$ group $(\mathrm{p}<0.001)$, and 4 -fold lower than that of the 5FU/WT-IMC group $(p<0.0001)$. Of note, this analysis underestimates the true differences in tumor sizes because four tumors in the $5 \mathrm{FU}$ group and four tumors in the $5 \mathrm{FU} / \mathrm{WT}$-IMC group had already reached $2 \mathrm{~cm}$ and required euthanasia prior to day 28 (figure 3C, top). These data indicate that adoptive transfer of p50-IMC, but not WT-IMC, slows PCa tumor growth when administered after a dose of $5 \mathrm{FU}$.

Comparison of modelled tumor growth between the untreated and p50-IMC alone groups revealed no significant difference in expected mean tumor volumes between day 15 and day 38, whereas 5FU/p50-IMC lead to significantly smaller (3- to 50-fold) expected mean tumor volumes on each of these days. Comparison of actual tumor volumes on day 25 confirms that there exists no difference between no treatment and p50-IMC alone; conversely, the mean tumor volume for the $5 \mathrm{FU} /$
p50-IMC group is 9-fold lower than that of the p50-IMC alone group (figure 3C, bottom). Thus, p50-IMC does not slow Hi-Myc PCa tumor growth without preceding $5 \mathrm{FU}$.

Since p50-IMC obtained by culture for 6 days with TPO/ SCF/FL and then for 1 day in M-CSF may include potential DC precursors, we examined whether culture with FL and low-dose GM-CSF rather than M-CSF could augment antitumor efficacy, as this cytokine combination favours DC formation from cultured marrow cells. ${ }^{29} \mathrm{p} 50$-IMC (GM+FL) retained an immature monocyte morphology, although with increased cytoplasmic granulation (online supplementary figure S1D). FC of p50-IMC (GM+FL) revealed a similar pattern of surface marker expression to that obtained with M-CSF, except that the Flt $3^{\text {hi }}$ population was less abundant, potentially reflecting down-regulated surface Flt3 due to excess FL (online supplementary figure $\mathrm{S} 1 \mathrm{E})$. In addition, the $\mathrm{CD} 115^{\mathrm{hi}}$ population contained 2-fold increased percentage of $\mathrm{F} 4 / 80^{+}$cells ( $30 \%$ vs $15 \%$ ), perhaps reflecting more rapid maturation. PCa tumor growth in individual mice treated with $5 \mathrm{FU}$ on day 13 followed by p50-IMC $(\mathrm{GM}+\mathrm{FL})$ on days 18,21 , and 25 is shown (figure $4 \mathrm{~A})$. 5FU/p50-IMC $(\mathrm{GM}+\mathrm{FL})$ data were obtained in the same experiment as a subset of data shown in figure 3 using $5 \mathrm{FU}$ alone and 5FU/p50-IMC(M-CSF).
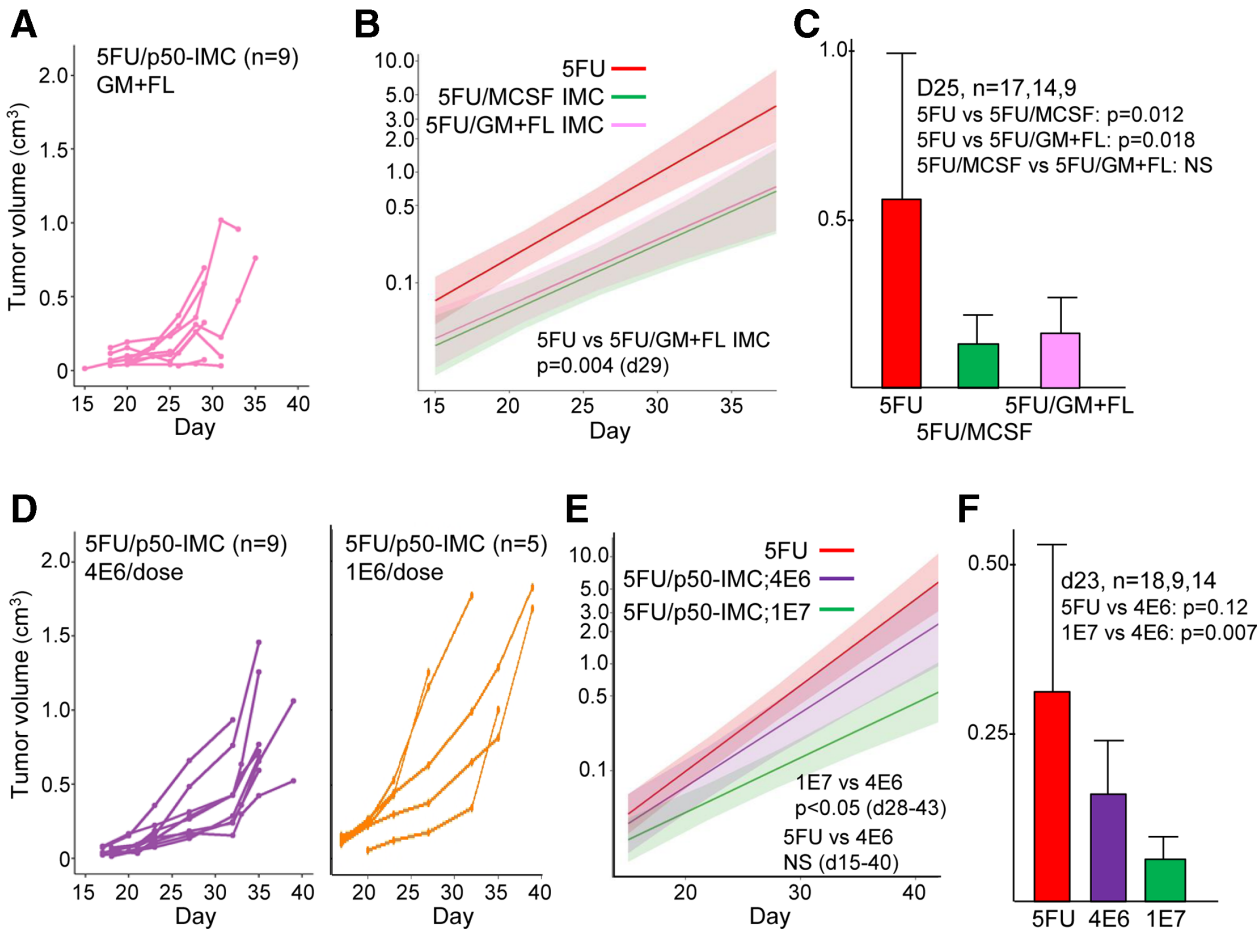

Figure 4 Efficacy of p50-IMC generated using FL and low-dose GM-CSF and p50-IMC dose-response. (A) Individual tumor volumes as measured every 2-4 days are shown for treatment with 5FU alone, 5FU/p50-IMC (M-CSF) or 5FU/p50-IMC $(\mathrm{GM}+\mathrm{FL})$. data are combined from two experiments. (B) These data were fit to an exponential model, with semilog plots and comparison of expected mean tumor volumes between the 5FU and 5FU/p50-IMC (GM+FL) groups on day 29. (C) Mean tumor volumes and SEs as measured on day 25 (or day 26) are shown. (D) Prostate cancer tumor growth data in response to 5FU followed by three doses of $4 \times 10^{6}$ or $1 \times 10^{6} \mathrm{p} 50-\mathrm{IMC}$ are shown, with data combined from two experiments. (E) These data and data from figure 3 for $5 F U$ alone were fit to an exponential model, with semilog plots and comparison of expected mean tumor volumes between the 5FU and 5FU/p50-IMC (4E6) groups shown for days 15-40. (F) Tumor volumes as measured on day 23 (or day 22) for these two groups are also compared. 5FU, 5-fluorouracil; FL, Flt3 ligand; GM, granulocyte-monocyte; GM-CSF, granulocyte-monocyte colony-stimulating factor; IMC, immature myeloid cell; M-CSF, monocyte colony-stimulating factor; NS, not significant; p50-IMC, p50-negative immature myeloid cell. 
Tumor volumes for these groups were fit to an exponential model (figure 4B), and measured tumor volumes on day 25 were compared (figure 4C), revealing that p50IMC generated using GM+FL are equally effective, but not more effective, than those generated using M-CSF.

We also examined whether a lower dose of p50-IMC per intravenous injection would be as effective as $10^{7} \mathrm{IMC}$ per dose. Cohorts of mice inoculated with $\mathrm{PCa}$ received a dose of 5FU on day 13 followed by three infusions of p50-IMC generated using M-CSF at either $4 \times 10^{6}$ or $1 \times 10^{6}$ cells per dose. Tumor growth in individual mice for these two groups is shown (figure $4 \mathrm{D}$ ). The $4 \times 10^{6}$ cell dose appeared more effective than the $1 \times 10^{6}$ cell dose. Analysis of the $5 \mathrm{FU} / \mathrm{p} 50-\mathrm{IMC}(4 \mathrm{E} 6)$ data in comparison with $5 \mathrm{FU} / \mathrm{p} 50-\mathrm{IMC}(1 \mathrm{E} 7)$ and $5 \mathrm{FU}$ data from figure 3 using the exponential model reveals that $5 \mathrm{FU}$ followed by p50-IMC(4E6) is not significantly better than 5FU alone between day 15 and day 40 (figure 4E), although a trend towards increased efficacy may exist, as indicated also by comparing tumor volumes on day 23, with a 2-fold $(p=0.12)$ difference (figure $4 F)$. These data also demonstrate that $5 \mathrm{FU} / \mathrm{p} 50-\mathrm{IMC}(1 \mathrm{E} 7)$ is more effective than $5 \mathrm{FU} / \mathrm{p} 50-\mathrm{IMC}(4 \mathrm{E} 6)$.
5FU followed by p50-IMC slows PDC tumor growth in $50 \%$ of mice

We also examined whether 5FU followed by M-CSFgenerated p50-IMC could slow PDC tumor growth. Luciferase-expressing KRas ${ }^{\text {G12D }}$ PDC was inoculated into the pancreatic tail of syngeneic albino B6 mice. Use of albino mice allows serial monitoring of tumor size by IVIS imaging, as requisite shaving of abdominal hair in black B6 mice leads to cutaneous pigment accumulation that obstructs imaging. In Experiment 1, 5FU was administered on day 7 , followed by $10^{7}$ p50-IMC on days 12 , 15 , and 19. In an effort to initiate therapy when tumors were smaller, in Experiments 2 and 3, 5FU was given on day three followed by WT-IMC or p50-IMC on days 8 , 11, and 14, as diagrammed (figure 5A). In Experiment 1 , two of five tumors manifested remarkable $\sim 10$ fold shrinkage in response to $5 \mathrm{FU} / \mathrm{p} 50-\mathrm{IMC}$, as estimated from relative tumor bioluminescence (and confirmed by abdominal examination); this was not evident in any of the tumors exposed to $5 \mathrm{FU}$ alone (figure $5 \mathrm{~B}$, left). In Experiment 2, two of five tumors showed 2- to 3-fold shrinkage from maximal size in response to $5 \mathrm{FU} / \mathrm{p} 50$ IMC, with four of five tumors showing no response to $5 \mathrm{FU} / \mathrm{WT}$-IMC (figure $5 \mathrm{~B}$, center). In experiment 3 , four of five tumors responded to $5 \mathrm{FU} / \mathrm{p} 50$-IMC more effectively than to $5 \mathrm{FU} / \mathrm{WT}$-IMC (figure $5 \mathrm{~B}$, right). Data from Experiments 2 and 3 were fit to an exponential model
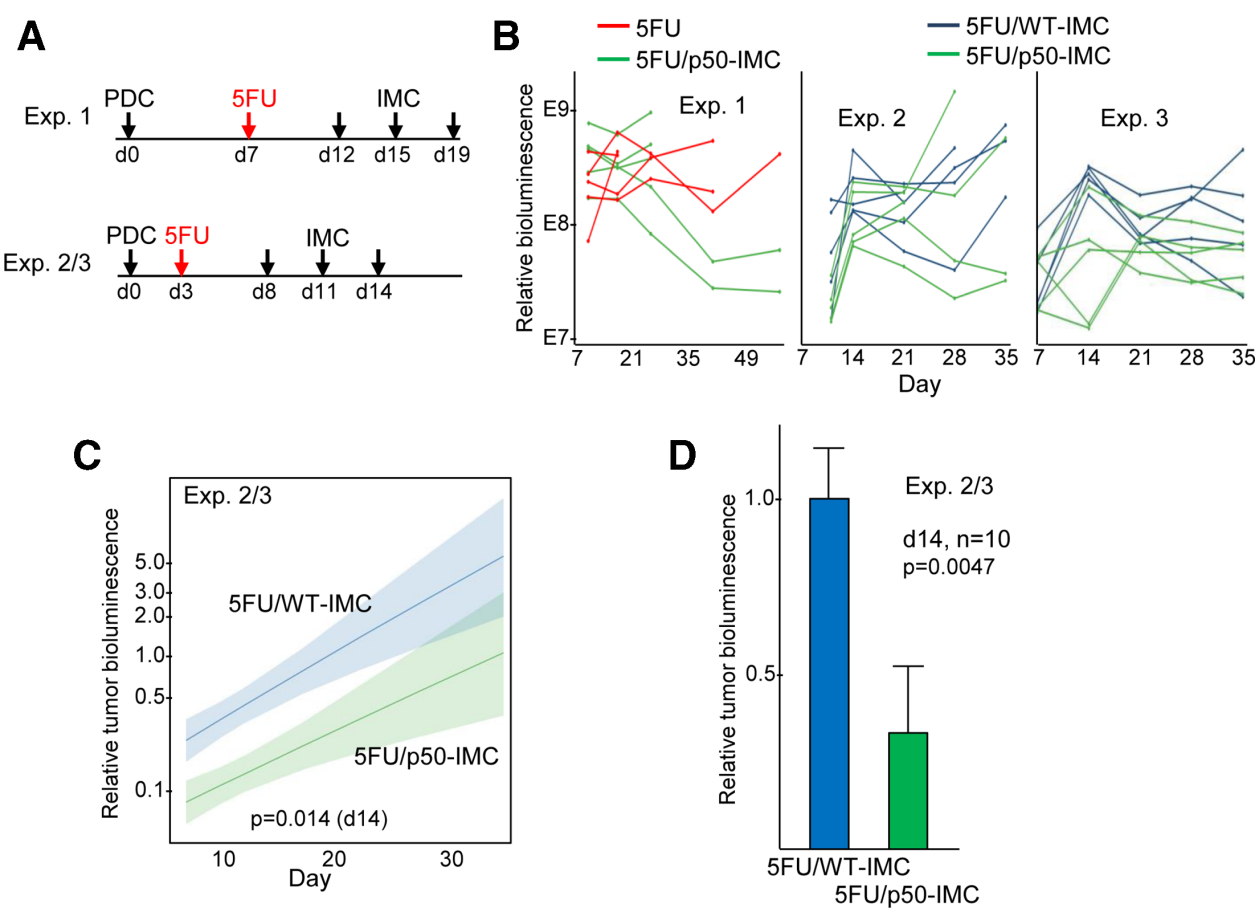

Figure 5 5FU followed by p50-IMC slows PDC tumor growth. (A) Albino mice inoculated orthotopically with K-Ras ${ }^{\text {G12D }}$ PDC on day 0 received 5FU on day 7 and $10^{7}$ WT-IMC or p50-IMC on days 12, 15 and 19 in Exp. 1 or 5FU on day 3 and IMC on days 8 , 11 and 14 in Exp. 2 and Exp. 3, as diagrammed. (B) Tumor sizes were monitored by serial in vivo imaging system imaging, with relative bioluminescence shown for each tumor in each experiment. (C) The data from Exp. 2/3 were fit to an exponential model, with semilog plots and comparison of expected mean tumor volumes between the 5FU/WT-IMC and 5FU/p50-IMC on day 14. (D) Mean tumor volumes and SEs as measured on day 14 for these same groups are shown. Exp. 1, experiment 1; Exp. 2, experiment 2; Exp. 3, experiment 3; 5FU, 5-fluorouracil; IMC, immature myeloid cell; p50-IMC, p50-negative immature myeloid cell; PDC, pancreatic ductal carcinoma; WT, wild type. 
A

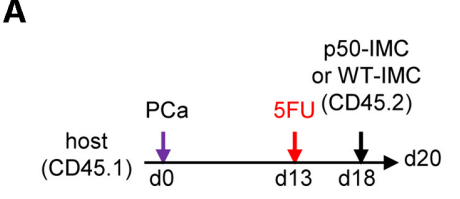

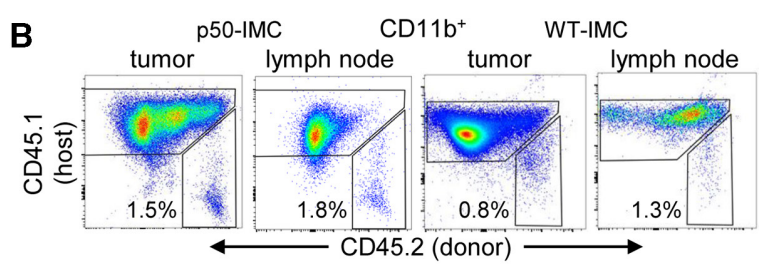
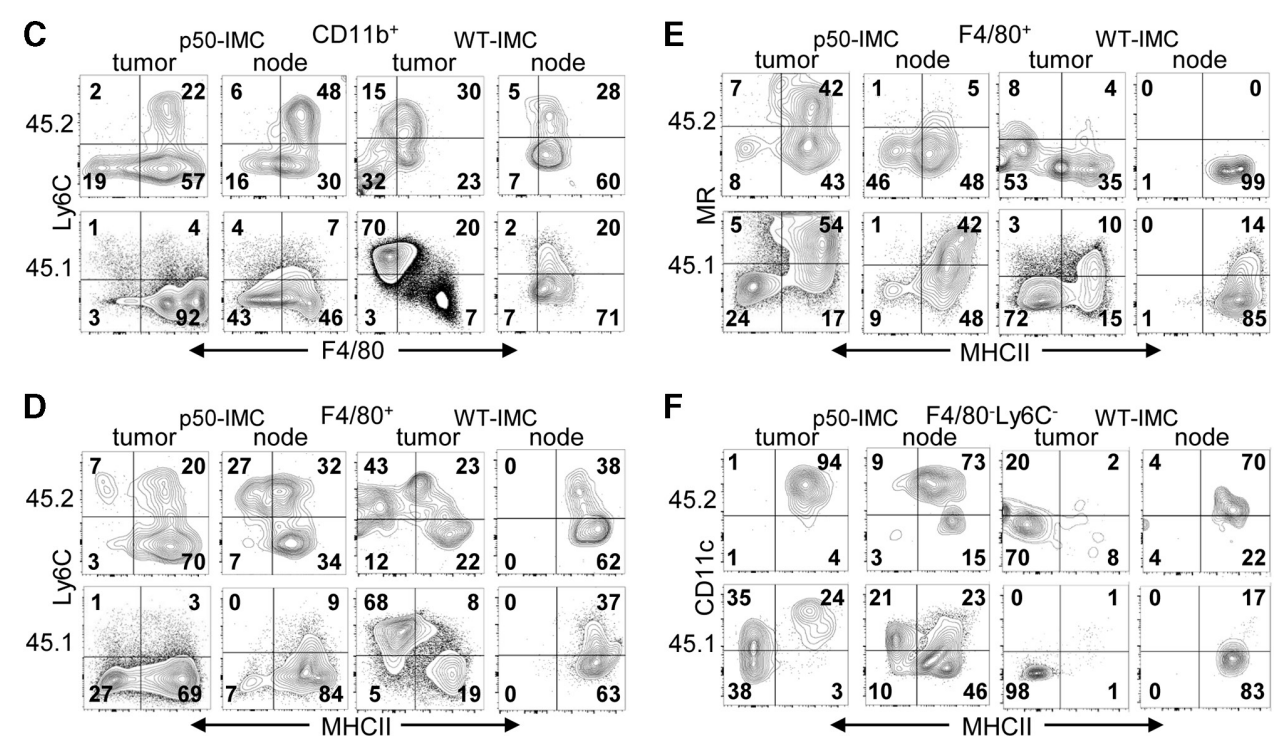

$\mathbf{F}$

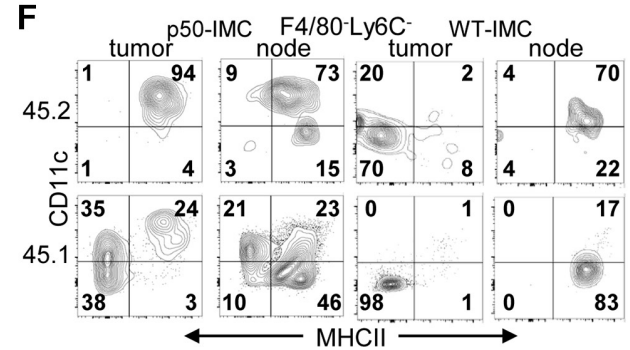

Figure 6 p50-IMC generates increased PCa tumor and lymph node myeloid cells and dendritic cells compared with WT-IMC. (A) CD45.1 $1^{+}$mice inoculated with PCa on day 0 received 5FU on day 13 and $10^{7}$ p50-IMC or WT-IMC derived from CD45.2 mice on day 18 , followed by tumor and inguinal lymph node mononuclear cell isolation and analysis on day 20, as diagrammed. Data acquired from $2 \times 10^{4} \mathrm{CD}_{11} \mathrm{~b}^{+}$cells per mouse from five mice in a single experiment were pooled for analysis. (B) CD $11 \mathrm{~b}^{+}$ myeloid cells were analyzed for CD45.2 (p50-IMC donor-derived) and CD45.1 (host) cells by flow cytometry. (C) IMC and host myeloid cells were analyzed for Ly6C and F4/80. (D) F4/80 myeloid cells within the CD45.2 $2^{+}$and $\mathrm{CD} 45.1^{+}$populations were analyzed for Ly6C and MHCII. (E) F4/80 myeloid cells within the CD45.2 ${ }^{+}$and $\mathrm{CD} 45.1^{+}$populations were analyzed for MR and MHCII. (F) F4/80- Ly6C $^{-}$myeloid cells within the CD45.2 $2^{+}$and CD45. $1^{+}$populations were analyzed for CD11c and MHCII. 5FU, 5-fluorouracil; IMC, immature myeloid cell; MHCII, Major Histocompatibility Complex II; MR, magnetic resonance; p50-IMC, p50-negative immature myeloid cell; PCa, prostate cancer; WT, wild type.

of tumor growth, with resulting semi-log plots of tumor volume versus time shown (figure 5C). Expected mean tumor volumes as predicted by the exponential model for the 5FU/p50-IMC group were 3-fold lower than those for the 5FU/WT-IMC group between days 11 and 21, with $\mathrm{p}=0.014$ on day 14 as shown. We also compared relative tumor bioluminescence on day 14 between the $5 \mathrm{FU} /$ WT-IMC and 5FU/p50-IMC groups from Experiments 2 and 3 (figure 5D). At this time, the mean tumor bioluminescence in the 5FU/p50-IMC group was 3-fold lower than that of the 5FU/WT-IMC group ( $\mathrm{p}=0.0047)$. Overall, these data demonstrate that $5 \mathrm{FU}$ followed by p50-IMC is effective against PDC, in some cases inducing substantial transient regression. However, the response of K-Ras ${ }^{\mathrm{G} 12 \mathrm{D}}$ PDC was less uniform than that of Hi-Myc PCa. Due to this variability, we focused on PCa for further analysis.

\section{p50-IMC generate PCa tumor and draining lymph node macrophages and DCs}

To evaluate myeloid cells that develop from a single dose of IMC, CD45.1 $1^{+}$B6 mice inoculated with Hi-Myc $\mathrm{PCa}$ received $5 \mathrm{FU}$ on day 13 followed by $10^{7} \mathrm{CD} 45.2^{+}$ p50-IMC or WT-IMC on day 18, with isolation of tumor and inguinal draining lymph nodes 2 days later, as diagrammed (figure 6A). As IMC contribution to total

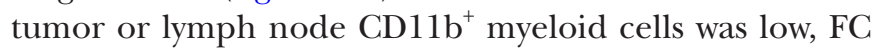
data acquired individually from four WT-IMC and five p50-IMC mice were pooled to generate the flow plots and populations frequencies shown. WT-IMC accounted for $0.8 \%$ of tumor and $1.3 \%$ of lymph node $\mathrm{CD} 11 \mathrm{~b}^{+}$myeloid cells, whereas p50-IMC comprised a higher proportion at $1.5 \%$ and $1.8 \%$, respectively (figure $6 \mathrm{~B}$ ). When data from the four WT-IMC and five p50-IMC mice are compared, the increased contribution of p50-IMC to nodal myeloid cells is significant $(\mathrm{p}=0.007)$. Consistent with data obtained with Luc-IMC, p50-IMC also localized to spleen and marrow, where they formed $7.7 \%$ and $11 \%$ of $\mathrm{CD} 11 \mathrm{~b}^{+}$myeloid cells, respectively (online supplementary figure S2a). Only $1.3 \%$ of tumor and $1.5 \%$ of nodal myeloid cells derived from p50-IMC were $\mathrm{Ly} 6 \mathrm{G}^{+}$neutrophils, while $2.2 \%$ of tumor and $5.8 \%$ of lymph node myeloid cells derived from WT-IMC were $\mathrm{Ly}_{6} \mathrm{G}^{+}$(online supplementary figure S2b).

The F4/80 macrophage marker was expressed on 53\% of tumor myeloid cells derived from WT-IMC and $79 \%$ of 
those derived from $\mathrm{p} 50$-IMC $(\mathrm{p}=0.001)$; in lymph nodes, however, the frequencies of IMC-derived $\mathrm{F} 4 / 80^{+}$macrophages $(88 \%$ vs $78 \%)$ were not significantly different (figure 6C). A substantial fraction of $\mathrm{F} 4 / 80^{+}$macrophages also expressed Ly6C, which is present on inflammatory monocytes and on both immune-activating and suppressive macrophages. ${ }^{30}$ As activated macrophages can co-express Ly6C with MHCII, we analyzed both markers (figure 6D). WT-IMC-derived macrophages co-expressed Ly6C and MHCII to a similar extent as p50-IMC-derived macrophages (23\% vs $20 \%$ in tumor and $38 \%$ vs $32 \%$ in lymph nodes), both not significant (NS). We also evaluated $\mathrm{F} 4 / 80^{+}$macrophages for mannose receptor (MR), a marker of tumor-promoting M2-polarized macrophages (figure 6E). In p50-IMC, macrophage MR was increased in tumor ( $49 \%$ vs $12 \%, \mathrm{p}=0.001)$ and decreased in lymph node $(6 \%$ vs $13 \%$, NS) compared with WT-IMC.

In addition to $\mathrm{F} 4 / 80^{+}$macrophages, IMC-derived myeloid cells included a population of $\mathrm{F} 4 / 80^{-} \mathrm{Ly}^{-} \mathrm{C}^{-}$cells; in tumor, their frequency was higher in WT-IMC than p50-IMC (32\% vs 19\%), whereas in lymph node their frequency was lower in WT-IMC than p50-IMC (7\% vs $16 \%$ ). F4/80 Ly6C cells were further evaluated for CD11c and MHCII, markers co-expressed on activated DCs (figure 6F). Strikingly, 94\% of p50-IMC-derived tumor F4/80'Ly6C cells co-expressed the CD11c and MHCII DC markers, compared with only $2 \%$ of WT-IMC-derived cells $(\mathrm{p}<0.001)$. Although the $73 \%$ frequency of $\mathrm{p} 50$-IMCderived and $70 \%$ frequency WT-IMC-derived CD11 $\mathrm{c}^{+} \mathrm{M}-$ $\mathrm{HCII}^{+}$DCs were similar in lymph node (figure $6 \mathrm{~F}$ ), the 2.3-fold increased frequency of the parent $\mathrm{F} 4 / 80 \mathrm{Ly}^{-} \mathrm{C}^{-}$ population indicates an overall increase in DCs derived from p50-IMC. Perhaps the greater overall frequency of CD45.2 $2^{+}$p50-IMC in the tumor and lymph node and the

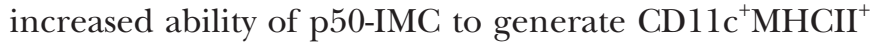
cDCs in tumor and lymph node accounts, in part, for the enhanced anti-tumor efficacy of p50-IMC compared with WT-IMC.

We also evaluated the effects of 5FU/p50-IMC on host CD 45. $1^{+}$myeloid cells. To establish a baseline, we characterized myeloid cell surface phenotypes in four tumorbearing mice that did not receive 5FU or IMC (online supplementary figure S3a). 5FU/p50-IMC increased total tumor $\mathrm{F} 4 / 80^{+}$macrophages from $79 \%$ in untreated to $96 \%(\mathrm{p}<0.001)$ in treated mice (online supplementary figure $\mathrm{S} 3 \mathrm{~b}$ ); however, among $\mathrm{F} 4 / 80^{+}$macrophages (online supplementary figure S3c), the proportion of $\mathrm{Ly}_{6 \mathrm{C}}{ }^{+} \mathrm{MHCII}^{+}$macrophages was reduced from $51 \%$ to $3 \%(\mathrm{p}<0.001)$. In lymph nodes, $5 \mathrm{FU} / \mathrm{p} 50-\mathrm{IMC}$ increased $\mathrm{F} 4 / 80^{+}$macrophages from $42 \%$ to $53 \%(\mathrm{p}=0.04)$, and reduced the $\mathrm{Ly}_{6} \mathrm{C}^{+} \mathrm{MHCII}^{+}$macrophage subpopulation from $66 \%$ to $9 \% \quad(\mathrm{p}<0.001)$. 5FU $/ \mathrm{p} 50$-IMC increased the proportion of $\mathrm{MR}^{+}$macrophages from $23 \%$ to $59 \%$ $(\mathrm{p}=0.001)$ in tumor and from $26 \%$ to $43 \% \quad(\mathrm{p}=0.006)$ in lymph nodes (online supplementary figure S3d). As shown (online supplementary figure S3e), 5FU/ p50-IMC did not significantly impact the proportion of F4/80-C11 ${ }^{+} \mathrm{MHCII}^{+}$DCs in tumor (31\% vs $24 \%$ ), but reduced this proportion in lymph nodes $(55 \%$ vs $23 \%$, $\mathrm{p}<0.001$ ). Finally, only $6.5 \%$ of tumor and $3.0 \%$ of nodal myeloid cells were $\mathrm{Ly} 6 \mathrm{G}^{+}$(online supplementary figure S3f). In sum, activation of host tumor or lymph node myeloid cells was not evident on day 20 in response to $5 \mathrm{FU} / \mathrm{p} 50$-IMC.

\section{$\mathrm{CD8}^{+} \mathrm{T}$ cell depletion attenuates the efficacy of $5 \mathrm{FU} / \mathrm{p} 50-\mathrm{IMC}$}

To evaluate the effect of 5FU/p50-IMC on host $\mathrm{T}$ cells, B6 mice inoculated with $\mathrm{Hi}-\mathrm{Myc} \mathrm{PCa}$ received 5FU on day 13 and then p50-IMC or WT-IMC on days 18, 21, and 25 , followed by tumor isolation and analysis on day 30 , as diagrammed (figure 7A, top). Day 30 analysis was chosen to allow time for $\mathrm{T}$ cell activation after the final p50-IMC infusion. CD $4^{+} \mathrm{T}$ cells represented $\sim 4 \%$ of viable cells within the tumor after either $5 \mathrm{FU} / \mathrm{WT}$-IMC or $5 \mathrm{FU} /$ p50-IMC. $\mathrm{CD}^{+} \mathrm{T}$ cells, however, which represented $3 \%$ of viable tumor cells after 5FU/WT-IMC, were 5-fold increased to $15 \%$ of viable tumor cells after $5 \mathrm{FU} / \mathrm{p} 50$-IMC (figure 7A, left). Intracellular IFN $\gamma$ staining demonstrated that $16 \%$ of $\mathrm{CD}^{+} \mathrm{T}$ cells derived from tumors exposed to $5 \mathrm{FU} / \mathrm{WT}$-IMC and $\sim 18 \%$ of $\mathrm{CD}^{+} \mathrm{T}$ cells in tumors treated with 5FU/p50-IMC were in an activated state at baseline. On PMA/ionomycin stimulation, the proportion of IFN $\gamma^{+}$ $\mathrm{CD}^{+} \mathrm{T}$ cells increased 1.5 -fold in mice receiving WT-IMC and nearly 3-fold in mice receiving p50-IMC (figure 7A, right). Together, the data for total and $\mathrm{IFN} \gamma^{+} \mathrm{CD}^{+} \mathrm{T}$ cells indicates that $5 \mathrm{FU} / \mathrm{p} 50$-IMC increases the total number of activated, tumor-associated $\mathrm{CD} 8^{+} \mathrm{T}$ cells and that these cells have a greater capacity to respond to signals that induce further $\mathrm{T}$ cell activation.

Given the striking increase in $\mathrm{PCa}$ tumor $\mathrm{CD}^{+} \mathrm{T}$ cells in mice receiving $5 \mathrm{FU} / \mathrm{p} 50$-IMC, we evaluated whether the efficacy of 5FU/p50-IMC was dependent on $\mathrm{CD} 8^{+} \mathrm{T}$ cells. B6 mice inoculated with $\mathrm{Hi}-\mathrm{Myc} \mathrm{PCa}$ received 5FU on day 13 followed by p50-IMC on days 18, 21, and 25 . One group of mice also received twice weekly injections of anti-CD8 antibody to deplete $\mathrm{CD} 8^{+} \mathrm{T}$ cells, beginning on day 17 , as diagrammed (figure $7 \mathrm{~B}$, top). Tumor volumes measured at individual time points for each mouse in these two experimental groups are shown (figure 7B, bottom). Data for mice that did not receive CD8 antibody comprise a subset of those shown in figure 3 and were obtained in the same experiments as the antibody-treated group. Three mice that developed ulceration prior to initiation of antibody treatment were censored from analysis. The data were fit to an exponential model of tumor growth, with the resulting semi-log plots of tumor volume versus time and their 95\% confidence intervals shown (figure 7C). Expected mean tumor volumes for the CD8 antibody-treated group were significantly higher (3- to 10-fold) than those for the control group between days 25 and 36 , with $\mathrm{p}=0.006$ on day 29 as shown. Comparison of measured tumor volumes on day 28 indicates a $>4$ fold increase in mean tumor size consequent to CD8 antibody treatment (figure 7D). We also evaluated the effect of CD8 antibody exposure, beginning on day 17, on PCa tumor growth in mice that did not receive 5FU or IMC. 
A
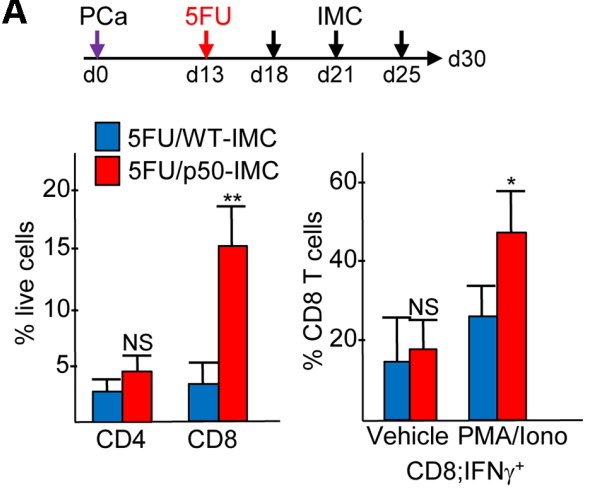

C

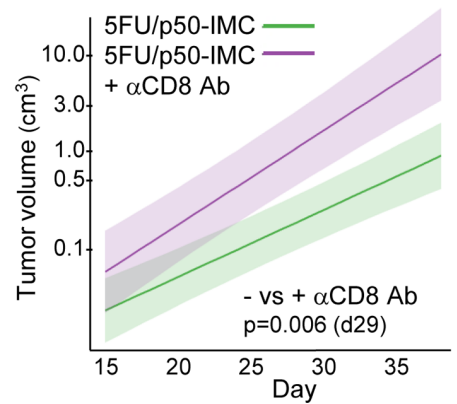

B
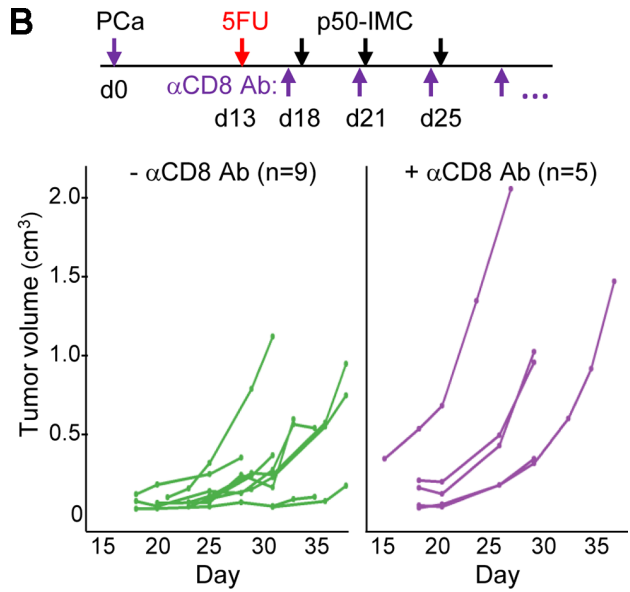

D

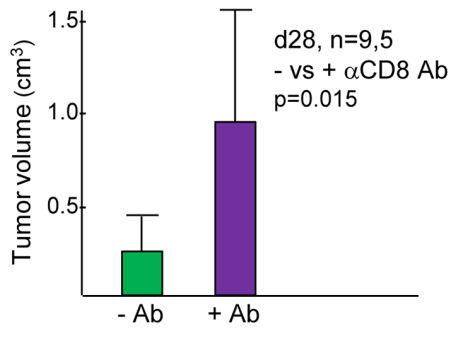

Figure 7 p50-IMC increases PCa tumor-activated $C D 8^{+} T$ cells numbers, and $C D 8^{+} T$ cells are required for efficacy of $5 F U /$ p50-IMC. (A) Mice inoculated with Hi-Myc PCa on day 0 received 5FU on day 13 and $10^{7}$ WT-IMC $(n=5)$ or p50-IMC $(n=4)$ on days 18,21 and 25 , followed by analysis of cells obtained from individual tumors on day 30 from a single experiment, as diagrammed. $\mathrm{CD}^{+} \mathrm{CD}^{+}$and $\mathrm{CD}^{+} \mathrm{CD} 8^{+} \mathrm{T}$ cells were enumerated as a percent of viable cells using flow cytometry (left). Single suspensions of tumor cells were placed in culture with DMEM/fetal bovine serum vehicle alone or with PMA/ionomycin for 4 hours, followed by analysis of $\mathrm{CD}^{+} \mathrm{CD}^{+} \mathrm{T}$ cells for intracellular IFN $\gamma$ (right). (B) Mice inoculated with Hi-Myc PCa on day 0 received 5FU on day 13 and $10^{7}$ WT-IMC or P50-IMC on days 18,21 and 25 with or without CD8 antibody treatment two times per day weekly starting on day 17 , as diagrammed. Individual tumor volumes as measured every 2-4 days, combined from two experiments, are shown. (C) These data were fit to an exponential model, with semilog plots and comparison of expected mean tumor volumes between the 5FU/p50-IMC and 5FU/p50-IMC plus anti-CD8 antibody ( $\alpha$ CD8 Ab) groups on day 29. (D) Tumor volumes as measured on day 18 for these two groups are also compared. 5FU, 5-fluorouracil; DMEM, Dulbecco's modified Eagle medium; IFN $\gamma$, interferon $\gamma$, IMC, immature myeloid cell; NS, not significant; p50-IMC, p50-negative immature myeloid cell; $\mathrm{PCa}$, prostate cancer; PMA, phorbol myristate acetate; WT, wild type.

Although FC confirmed effective $\mathrm{CD} 8^{+} \mathrm{T}$ cell depletion, there was no significant increase in tumor growth rate in the group that received $\mathrm{CD} 8$ antibody compared with the control group (online supplementary figure S4).

\section{DISCUSSION}

The key findings of this study are the following: 1) PCa and PDC cells grow slower in mice lacking NF- $\mathrm{KB}$ p50, as seen previously for melanoma, fibrosarcoma, colon cancer, and glioblastoma ${ }^{91516}$; 2) expansion of marrow myeloid progenitors from $\mathrm{p} 50^{-/-}$mice followed by transfer to M-CSF for 1 day yields IMC that localize to PCa or PDC tumors, regional lymph nodes, marrow, spleen, and lung; 3) administration of $5 \mathrm{FU}$ followed by adoptive transfer of p50-IMC, but not WT-IMC, slows the growth of a larger majority of subcutaneous PCa tumors and approximately half of orthotopic PDC tumors, often inducing striking PDC regression in responders; 4) p50-IMC generated using low-dose GM-CSF and FL to favour DC formation also slows PCa growth; 5) p50-IMC generate activated tumor and lymph node macrophages and DCs, but do not activate endogenous tumor myeloid cells; and 6) p50-IMC induce $\mathrm{CD} 8^{+} \mathrm{T}$ cell activation, and $\mathrm{CD} 8^{+} \mathrm{T}$ cell depletion reduces efficacy of p50-IMC. p50-IMC was not effective without preceding $5 \mathrm{FU}$, potentially reflecting the ability of $5 \mathrm{FU}$ to decrease competition from marrow production of blood monocytes, to deplete immune-suppressive tumor myeloid cells, or to release tumor neoantigens that contribute to $\mathrm{CD}^{+} \mathrm{T}$ cell activation. ${ }^{21}{ }^{22}$ Indeed, our data show that PCa tumors grew slower on average in 5FU compared with no therapy. In the clinical setting, a chemotherapy agent other than $5 \mathrm{FU}$ might be chosen that both transiently reduces marrow blood cell production and has efficacy against the patient's malignancy.

Paralleling our finding that efficacy of 5FU/p50-IMC is diminished on $\mathrm{CD}^{+} \mathrm{T}$ cell depletion, simultaneous depletion of $\mathrm{CD}^{+}$and $\mathrm{CD} 8^{+} \mathrm{T}$ cells increased the burden of colon cancer in $\mathrm{p} 50^{-/-}$mice to that of WT mice in response to azoxymethane/dextran sodium sulfate exposure, ${ }^{15}$ and $\mathrm{CD} 4^{+} \mathrm{T}$ cell depletion fully and $\mathrm{CD} 8^{+} \mathrm{T}$ cell 
depletion partially eliminated the survival advantage of $\mathrm{p} 50^{-/-}$mice inoculated intra-cranially with glioblastoma. ${ }^{16}$

Adoptive transfer of activated macrophages has been evaluated in cancer patients, as recently reviewed. ${ }^{28}$ In the majority of trials, blood monocytes collected by leukopheresis were matured and activated by culturing for 6 days in GM-CSF and then for 18 hours with IFN $\gamma$. Although well tolerated, the majority of Indium ${ }^{11}$. labelled macrophages localizing to the lung and there was minimal anti-tumor efficacy. Perhaps use of less mature myeloid cells capable of trafficking to the tumor microenvironment and regional nodes contributes to the tumor responses we observe. Our dose of $10^{7}$ IMC per $30 \mathrm{gm}$ mouse corresponds to $3.3 \times 10^{8}$ cells $/ \mathrm{kg}$ or $1.7 \times 10^{10}$ cells for a $50 \mathrm{~kg}$ adult, in contrast to the $10^{9}$ macrophages used in human trials. This dose should be readily achievable through expansion of marrow $\mathrm{CD} 34^{+}$cells, as human peripheral blood or marrow stem cell harvest typically yields at least $2 \times 10^{6} \mathrm{CD} 34^{+}$cells $/ \mathrm{kg},{ }^{31}$ and culture of cord blood CD $34^{+}$cells with TPO, SCF, FL, IL-6, IL-3, and Notch Ligand for 14-16 days leads to almost 1,000-fold expansion. ${ }^{32}$ We have seen similar expansion on culture of adult marrow CD $34^{+}$cells with TPO, SCF, FL, and IL-6, SR1, and UM171, which was increased to more than 100,000 -fold by continued culture. Of note, we have seen no toxicity of p50-IMC in tumor-bearing mice.

p50 directly represses the genes encoding proinflammatory TNF $\alpha$, IL-8, Mmp13, Cox-2, Ccl2, Ccl10, GM-CSF, and IFN $\beta$ and induces the gene encoding antiinflammatory IL-10. ${ }^{33-37}$ Deletion of p50 in IMC likely impacts these factors and contributes to activation of resulting macrophages and DCs. ${ }^{9-16}$ Consistent with this idea, we find that p50-IMC generate tumor and lymph node macrophages that co-express Ly6C and MHCII, a combination indicative of activated, tumor suppressive macrophages. ${ }^{28}{ }^{38-40}$ We previously found increased $\mathrm{Ly}_{6 \mathrm{C}^{+}} \mathrm{MHCII}^{+}$tumor macrophages in glioblastomas developing in the central nervous system of $\mathrm{p} 50^{-/-}$compared with WT hosts, associated with reduced glioblastoma tumor growth. ${ }^{16}$ We also find that p50-IMC generate tumor and lymph node $\mathrm{CD} 11 \mathrm{~b}^{+} \mathrm{F} 4 / 80^{-} \mathrm{CD} 11 \mathrm{c}^{+} \mathrm{MHCII}{ }^{+}$ cDCs, which are likely also activated due to de-repression of pro-inflammatory NF- $\mathrm{kB}$ target genes. Of note, p50IMC did not activate endogenous tumor myeloid cells. Adoptive transfer of monocytes expressing exogenous IFN $\alpha$ leads to anti-tumor responses in breast cancer and glioblastoma models. ${ }^{41}{ }^{42}$ p50-IMC might be even more effective due to activation of a broad pro-inflammatory gene expression programme consequent to absence of NF-KB p50.

In addition to PCa and PDC, p50-IMC has the potential to contribute to the therapy of multiple malignancies. For clinical translation, we envision gene editing of patient marrow or peripheral blood $\mathrm{CD} 34^{+}$cells as they expand in TPO, SCF, and FL, followed by culture for 1 day in M-CSF or other myeloid cytokines. Patient-derived induced pluripotent stem cells engineered to lack p50 might alternatively serve as a continuous p50-IMC source.

\section{CONCLUSIONS}

5 FU followed by adoptive transfer of p50-IMC slows the growth of murine prostate and PDC. Infused myeloid cells generate activated tumor and lymph node macrophages and DCs and induce $\mathrm{CD}^{+} \mathrm{T}$ cell-mediated anti-tumor immunity. Adoptive transfer of patient-derived NF- $\kappa \mathrm{B}$ p50-deficient IMC, potentially generated by expansion and gene editing of marrow $\mathrm{CD} 34^{+}$cells, may contribute to the therapy of these and additional cancers.

Acknowledgements We thank Brian W Simons for the B6 Hi-Myc PCa cell line and Surinder K Batra for the B6 UN-KC-1641 K-Ras ${ }^{\text {G12D; }}$;dx1-Cre PDC cell line.

Contributors Study design, manuscript preparation and final approval of manuscript: all authors. Study conduct, data collection and data analysis: RS, DJB, TB and ADF.

Funding This work was supported by a V Foundation Translational Award (ADF), by Department of Defense grant PC150202 (ADF), by National Institutes of Health grants T32 CA60441 (DJB) and P30 CA006973, and by The Giant Food Children's Cancer Research Fund.

Competing interests ADF is a named inventor on a PCT patent application entitled 'NF- $\mathrm{kB}$ p50 Deficient Immature Myeloid Cells and Their Use in Treatment of Cancer' filed by The Johns Hopkins University.

Patient consent for publication Not required.

Ethics approval This study was approved by the Johns Hopkins University Animal Care and Use Committee (protocol M016M66, 03/04/2016).

Provenance and peer review Not commissioned; externally peer reviewed.

Data availability statement Data are available upon reasonable request. The datasets used and/or analyzed during the current study are available from the corresponding author on reasonable request.

Open access This is an open access article distributed in accordance with the Creative Commons Attribution Non Commercial (CC BY-NC 4.0) license, which permits others to distribute, remix, adapt, build upon this work non-commercially, and license their derivative works on different terms, provided the original work is properly cited, appropriate credit is given, any changes made indicated, and the use is non-commercial. See http://creativecommons.org/licenses/by-nc/4.0/.

\section{ORCID iD}

Alan D Friedman http://orcid.org/0000-0002-5615-7061

\section{REFERENCES}

1 Mosser DM, Edwards JP. Exploring the full spectrum of macrophage activation. Nat Rev Immunol 2008;8:958-69.

2 Noy R, Pollard JW. Tumor-associated macrophages: from mechanisms to therapy. Immunity 2014;41:49-61.

3 Pyonteck SM, Akkari L, Schuhmacher AJ, et al. Csf-1R inhibition alters macrophage polarization and blocks glioma progression. Nat Med 2013;19:1264-72.

4 Strachan DC, Ruffell B, Oei Y, et al. CSF1R inhibition delays cervical and mammary tumor growth in murine models by attenuating the turnover of tumor-associated macrophages and enhancing infiltration by $\mathrm{CD}^{+}$T cells. Oncoimmunology 2013;2:e26968.

5 Quail DF, Bowman RL, Akkari L, et al. The tumor microenvironment underlies acquired resistance to CSF-1R inhibition in gliomas. Science 2016;352:aad3018.

6 Karin M, Ben-Neriah Y. Phosphorylation meets ubiquitination: the control of NF-кB activity. Annu Rev Immunol 2000;18:621-63.

7 Heissmeyer V, Krappmann D, Wulczyn FG. NF-кB p105 is a target of $\mathrm{I} \kappa \mathrm{B}$ kinases and controls signal induction of Bcl-3-p50 complexes. Embo J 1999;18:4766-78.

8 Williams SA, Chen L-F, Kwon $\mathrm{H}$, et al. NF-кB p50 promotes HIV latency through HDAC recruitment and repression of transcriptional initiation. Embo J 2006;25:139-49.

9 Saccani A, Schioppa T, Porta C, et al. p50 nuclear factor- $\kappa B$ overexpression in tumor-associated macrophages inhibits M1 inflammatory responses and antitumor resistance. Cancer Res 2006;66:11432-40.

10 Porta C, Rimoldi M, Raes G, et al. Tolerance and M2 (alternative) macrophage polarization are related processes orchestrated 
by p50 nuclear factor kappaB. Proc Natl Acad Sci U S A 2009;106:14978-83.

11 Kono Y, Kawakami S, Higuchi Y, et al. In vitro evaluation of inhibitory effect of nuclear factor-kappaB activity by small interfering RNA on pro-tumor characteristics of M2-like macrophages. Biol Pharm Bull 2014;37:137-44.

12 Rackov G, Hernández-Jiménez E, Shokri R, et al. P21 mediates macrophage reprogramming through regulation of p50-p50 NF- $\kappa B$ and IFN- $\beta$. J Clin Invest 2016;126:3089-103.

13 Dissanayake D, Hall H, Berg-Brown N, et al. Nuclear factor- $\kappa B 1$ controls the functional maturation of dendritic cells and prevents the activation of autoreactive T cells. Nat Med 2011;17:1663-7.

14 Larghi P, Porta C, Riboldi E, et al. The p50 subunit of NF- $\mathrm{B}$ orchestrates dendritic cell lifespan and activation of adaptive immunity. PLoS One 2012;7:e45279.

15 Porta C, Ippolito A, Consonni FM, et al. Protumor steering of cancer inflammation by p50 NF- $\mathrm{KB}$ enhances colorectal cancer progression. Cancer Immunol Res 2018;6:578-93.

16 Barberi T, Martin A, Suresh R, et al. Absence of host NF- $\kappa B$ p50 induces murine glioblastoma tumor regression, increases survival, and decreases $T$ cell induction of tumor-associated macrophage M2 polarization. Cancer Immunol Res 2018;67:1491-503.

17 Nonomura N, Takayama H, Nakayama M, et al. Infiltration of tumourassociated macrophages in prostate biopsy specimens is predictive of disease progression after hormonal therapy for prostate cancer. BJU Int 2011;107:1918-22.

18 Yu M, Guan R, Hong W, et al. Prognostic value of tumor-associated macrophages in pancreatic cancer: a meta-analysis. Cancer Manag Res 2019;11:4041-58.

19 Koehn BH, Apostolova P, Haverkamp JM, et al. GVHD-associated, inflammasome-mediated loss of function in adoptively transferred myeloid-derived suppressor cells. Blood 2015;126:1621-8.

20 Francke A, Herold J, Weinert S, et al. Generation of mature murine monocytes from heterogeneous bone marrow and description of their properties. J Histochem Cytochem 2011;59:813-25.

21 Zhang J, Li L, Baldwin AS, et al. Loss of IKK $\beta$ but not NF- $\kappa B$ p65 skews differentiation towards myeloid over erythroid commitment and increases myeloid progenitor self-renewal and functional longterm hematopoietic stem cells. PLoS One 2015;10:e0130441.

22 Vincent J, Mignot G, Chalmin F, et al. 5-Fluorouracil selectively kills tumor-associated myeloid-derived suppressor cells resulting in enhanced T cell-dependent antitumor immunity. Cancer Res 2010;70:3052-61.

23 Barakat DJ, Suresh R, Barberi T, et al. Absence of myeloid KLF4 reduces prostate cancer growth with pro-atherosclerotic activation of tumor myeloid cells and infiltration of CD8 T cells. PLoS One 2018;13:e0191188.

24 Torres MP, Rachagani S, Souchek JJ, et al. Novel pancreatic cancer cell lines derived from genetically engineered mouse models of spontaneous pancreatic adenocarcinoma: applications in diagnosis and therapy. PLoS One 2013;8:e80580.

25 Therneau TM, Lumley T. A package for survival analysis in S. version 2.38. Available: https://CRAN.R-project.org/package=survival [Accessed 3 Jul 2017].
26 Bates D, Mächler M, Bolker B, et al. Fitting Linear Mixed-Effects Models Using Ime4. J Stat Softw 2015;67:1-48.

27 Lenth R, Singmann H, Love J, et al. emmeans: estimated marginal means, AKA least-squares means. Available: https://cran.r-project. org/web/packages/emmeans/index.html [Accessed 24 Feb 2018].

28 Lee S, Kivimäe S, Dolor A, et al. Macrophage-based cell therapies: the long and winding road. J Control Release 2016;240:527-40.

29 Mayer CT, Ghorbani P, Nandan A, et al. Selective and efficient generation of functional Batf3-dependent CD103+ dendritic cells from mouse bone marrow. Blood 2014;124:3081-91.

30 Geissmann F, Manz MG, Jung S, et al. Macrophages, and dendritic cells. Science 2010;327:656-61.

31 Hosing C, Saliba RM, Hamerschlak N, et al. Peripheral blood stem cell yield calculated using preapheresis absolute CD34+ cell count, peripheral blood volume processed, and donor body weight accurately predicts actual yield at multiple centers. Transfusion 2014;54:1081-7.

32 Delaney C, Milano F, Cicconi L, et al. Infusion of a non-HLA-matched ex-vivo expanded cord blood progenitor cell product after intensive acute myeloid leukaemia chemotherapy: a phase 1 trial. Lancet Haematol 2016;3:e330-9.

33 Kastenbauer S, Ziegler-Heitbrock HW. NFкB1 (p50) is upregulated in lipopolysaccharide tolerance and can block tumor necrosis factor gene expression. Infect Immun 1999;67:1553-9.

34 Tong X, Yin L, Washington R, et al. The p50-p50 NF- $\kappa B$ complex as a stimulus-specific repressor of gene activation. Mol Cell Biochem 2004;265:171-83.

35 Elsharkawy AM, Oakley F, Lin F, et al. The NF-кB p50:p50:HDAC-1 repressor complex orchestrates transcriptional inhibition of multiple pro-inflammatory genes. J Hepatol 2010;53:519-27.

36 Cheng CS, Feldman KE, Lee J, et al. The specificity of innate immune responses is enforced by repression of interferon response elements by NF-кB p50. Sci Signal 2011;4:ra11.

37 Cao S, Zhang X, Edwards JP, et al. NF-кB1 (p50) homodimers differentially regulate pro- and anti-inflammatory cytokines in macrophages. J Biol Chem 2006;281:26041-50.

38 Movahedi K, Laoui D, Gysemans C, et al. Different tumor microenvironments contain functionally distinct subsets of macrophages derived from Ly6C(high) monocytes. Cancer Res 2010;70:5728-39.

39 Georgoudaki A-M, Prokopec KE, Boura VF, et al. Reprogramming tumor-associated macrophages by antibody targeting inhibits cancer progression and metastasis. Cell Rep 2016;15:2000-11.

40 Marigo I, Zilio S, Desantis G, et al. T cell cancer therapy requires CD40-CD40L activation of tumor necrosis factor and inducible Nitric-Oxide-Synthase-Producing dendritic cells. Cancer Cell 2016;30:377-90

41 De Palma M, Mazzieri R, Politi LS, et al. Tumor-Targeted interferon- $\alpha$ delivery by Tie2-expressing monocytes inhibits tumor growth and metastasis. Cancer Cell 2008;14:299-311.

42 Escobar G, Moi D, Ranghetti A, et al. Genetic engineering of hematopoiesis for targeted IFN- $\alpha$ delivery inhibits breast cancer progression. Sci Trans/ Med 2014;6:217ra3. 